
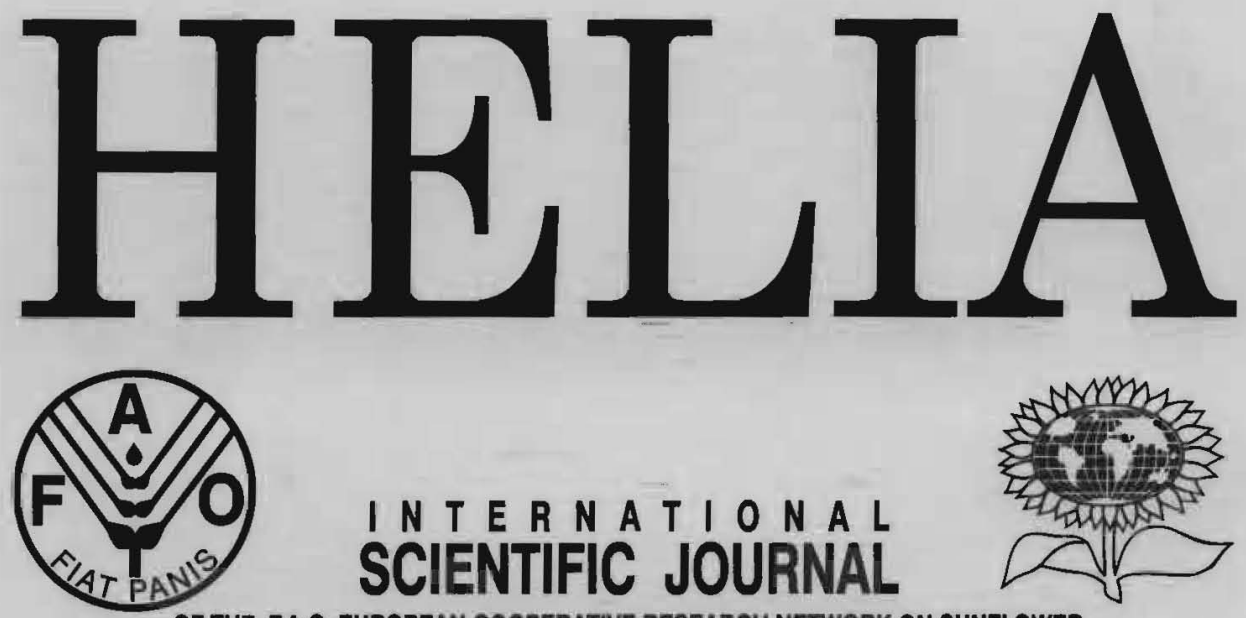

I N T E R N A T I O N A L SCIENTIFIC JOURNAL

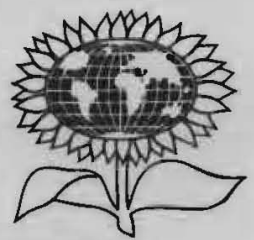

OF THE F.A.O. EUROPEAN COOPERATIVE RESEARCH NETWORK ON SUNFLOWER

AND THE INTERNATIONAL SUNFLOWER ASSOCIATION 


\title{
FIRST APPEARANCE OF WHITE MOULD ON SUNFLOWER CAUSED BY Sclerotinia minor IN THE REPUBLIC OF MACEDONIA
}

\author{
Karov, I. ${ }^{*}$, Mitrev, S. ${ }^{1}$, Mas̆irević, S. ${ }^{2}$, Kovacevik, B. ${ }^{1}$
}

${ }^{I}$ Department for plant and environment protection, Faculty of Agriculture, University of Goce Delcev - Shtip, 2000 Shtip, Republic of Macedonia

${ }^{2}$ Faculty of agriculture. University of Novi Sad, Square Dositeja Obradovića 8.

21000 Novi Sad. Republic of Serbia

Received: February 15, 2011 Accepted: May 10, 2011

\section{SUMMARY}

Sclerottnia spp. a very destructive fungus causing "white mould" became one of the biggest problems in sunflower breeding in the Republic of Macedonia in 2010. Field monitoring in the region of Bitola show very high infection of around $20-30 \%$. Two types of symptoms where observed during the field monitoring. First symptoms were observed on the leaves of the infected plants in the form of wilting, prior to flowering stage. The most characteristic symptoms were observed, at the lower part of the stem in the form of a stem cancer. Big variable sclerotia in size and shape were observed inside the stem. The appearance of white mycelium on the infected lower parts of the plant was often observed during the wet weather. Other infected plants showed different symptoms. The stem was longer and thinner than in uninfected plants, and the pit was very small, around $9 \mathrm{~cm}$. Sclerotia observed inside the stem were not bigger than $2.5 \mathrm{~mm}$. ln vitro investigations confirmed the presence of ascomycetes Sclerotinia sclerotiorum (Lib.) de Bary and Sclerotinia minor Jagger, for the first time in the Republic of Macedonia.

In vitro investigation of antifungal ability of Pseudomonas mediterranea Cattara et al., 2002 against S. sclerotiorum and S. minor showed that it can be a possible antifungal agent against these ascomycetes.

Key words: Sclerotinia sclerotiorum, Sclerotinia minor, sclerotia, symptoms, in vitro investigations

\section{INTRODUCTION}

Sunflower (Helianthus annuus L.), is an important oilseed plant in food industries for production of vegetable oils. In 2009 sunflower crop in Republic of Macedonia was sown on almost 4211 ha, mostly in the region of Bitola (3170 ha) (Statistical review, 2009; Table 1). Field monitoring showed the presence of white

* Corresponding author: Phone: +384 32550 601; e-mail: ilija.karov@ugd.edu.mk 
mould in the regions of Bitola, Prilep, Lozovo, Kumanovo and St. Nikola. This was the first observation of the presence of this disease in the Republic of Macedonia. Several plant pathogens are identified as the cause of white mould in sunflower crop: Sclerotinia sclerotiorum (Lib.) De Bary. Sclerotinia minor Jagger and Sclerotinia trifoliorum Eriks (Prudy, 1979: Nelson and Lamey, 2000; Gulya et al., 1997). Therefore it was of great interest to identify the specific pathogen that caused the disease in Macedonia. S. sclerotiorum is an aggressive fungal agent which attacks and infects nearly 400 plant species (Prudy, 1979: Maširević \& Gulya, 1992; Boland \& Hall, 1994; Melzer et al., 1997). The fungus cause head and stem rot in sunflower and survive as sclerotia in soil. Sclerotia can germinate carpogenic in apothecia, and myceliogenic in mycelium (Duane, L.T., 1979; Huang \& Chi, 2003). Apothecia produce asci that release ascospores which cause primary infections in spring. Both ascospores and mycelia can case infection. S. minor and S. trifoliorum can cause very similar symptoms, and it is very difficult to distinguish them according to the symptoms in the field. They can be identified by their cultural, biological, macroscopic and microscopic characteristics. In order to find some new methods which would decrease the application of fungicide, an in vitro research was conducted using the bacterium Pseudomonas mediterranea (Cattara et al., 2002). Pseudomonas mediterranea is tomato and pepper plant pathogen that cause pith necrosis. Hence it is closely related to Pseudomonas corrugata (Scarlet et al., 1978) a successfully tested biological agent. We investigated the antifungal activity of $P$. mediterranea against Sclerotinia sclerotiorum and S. minor in in vitro conditions. The bacterium does not attack sunflower (Helianthus annuus L.), thus we assumed it could be successfully used as a blological control agent against "white mould" in sunflower plants. The aim of this study was to identify the pathogens causing white mould at sunflower in the Republic of Macedonia and to investigate in vitro a new, environmentally friendly method to suppress the infection.

\section{MATERIALS AND METHODS}

\section{Field investigation}

The monitoring was performed in the regions of Bitola, Prilep, Kumanovo, Gradsko, Lozovo and St. Nikola in the flowering stage and in the stage of maturing of the plants (Table 1). Samples of diseased material were collected and investigated in in vitro conditions.

Table 1: Review of the investigated regions

\begin{tabular}{llcc}
\hline Region of production & Area / ha & Infection \% \\
\hline 1 & Bitola & 3170 & $28-30$ \\
2 & St. Nicole & 127 & $18-22$ \\
3 & Lozovo & 188 & 21 \\
4 & Kumanovo & 305 & $10-13$ \\
5 & Gradsko & 125 & - \\
6 & Prilep & 26 & $18-20$ \\
\hline
\end{tabular}




\section{Isolation of the pathogen}

Mycelium from diseased plant parts was transferred to PDA medium containing streptomycin for bacteria suppression. Sclerotia were well washed in sink water, sterilized in $1 \% \mathrm{NaOCl}$ for $2-3 \mathrm{~min}$ and transferred to a Petri dish containing PDA. Ten isolates from sunflower where included for investigation of the pathogen (Table 2). Petri dishes were put in growth chambers at temperature of $22^{\circ} \mathrm{C}$ and in darkness in order for mycelium growth and sclerotia to form. The identification of the pathogen was made by its macroscopic, cultural, biological and microscopic characteristics (Kohn, 1979).

Table 2: Review of the isolates used in this study

\begin{tabular}{lllll}
\hline Isolate & & Variety & Oregin & Area \\
\hline 1 & ss-1 & S. sclerotiorum & Helianthus annuus & Prilep \\
2 & ss-2 & S. sclerotiorum & Helianthus annuus & Prilep \\
3 & ss-3 & S. sclerotiorum & Helianthus annuus & Bitola \\
4 & ss-4 & S. sclerotiorum & Helianthus annuus & Bitola \\
5 & ss-5 & S. sclerotiorum & Helianthus annuus & Bitola \\
6 & sm-1 & S. minor & Helianthus annuus & Kumanovo \\
7 & sm-2 & S. minor & Helianthus annuus & Bitola \\
8 & sm-3 & S. minor & Helianthus annuus & St. Nikole \\
9 & sm-4 & S. minor & Helianthus annuus & St. Nikole \\
10 & sm-5 & S. minor & Helianthus annuus & Lozovo \\
11 & P.m 09/1 & P. mediterranea & L. esculentum & Strumica \\
12 & P.m 09/2 & P. mediterranea & L. esculentum & Strumica \\
13 & Pm S1 & P. mediterranea & Soil & Strumica \\
14 & Pm S2 & P. mediterranea & Soil & Strumica \\
\hline
\end{tabular}

\section{S. sclerotiorum inoculum and carpogenically germination of sclerotia}

Sclerotia inside the stem and on the root were washed in water and air dried at room temperature for 7 days so that it could germinate and the apothecia could form. Dry sclerotia were then buried in $1-2 \mathrm{~cm}$ deep in autoclaved sand (B.M. Wu et al. 2007). The dishes were then transferred to growth chambers at the temperature of $18-20^{\circ} \mathrm{C}$, for 12 hour periods of light and dark and $30 \% \mathrm{RH}$ (Cobb \& Dillard, 2007). The sand was watered daily and the condensation formed on the underside of the Petri dish lid was uncapped with sterile filter paper. The same procedure was implemented with the sclerotia formed on PDA in vitro.

\section{Bacterial isolates}

Four isolates of Pseudomonas mediterranea obtained from tomato plants and soil (Table 2) were investigated for their antifungal efficacy. Bacteria were isolated from tomato plants showing symptoms of tomato pith necrosis and from soil where infected tomato plants were grown. Bacteria were maintained on medium NA and at $27^{\circ} \mathrm{C}$. 


\section{Antifungal efficacy of $P$. mediterranea}

For in vitro investigation of antifungal efficacy of $P$. mediterranea one sclerotia, per isolate was put in the centre of the Petri dish containing PDA medium and one day old bacteria were spread by touch onto the some Petri dish in three places. The experiment was conducted in three repetitions for each investigated isolate.

\section{RESULTS}

\section{Field investigation}

The first symptoms were observed in the flowering stage in the form of leaf wilting. The infected leaves became yellow, turned brown, and died. Characteristic symptoms where observed at the base of the stem in form of the cancer. Numerous sclerotia of different shapes and sizes were noticed on the root and inside the stem and the pith was totally destroyed (Figure 2). The presence of white mycelium was observed in the infected plant parts. Other symptoms observed were: tiny longer than usual stems with black lesions that spread onto the large surface of the steam. A great number of black and light brown sclerotia not bigger than $2.5 \mathrm{~mm}$ were present inside the stem and on the lower part of the stem, too (Figure 3). Sclerotia inside the stem were more circular comparing to the sclerotia observed on the stem which were more angular. The pith of the plant was smaller than usual with a diameter of around $9 \mathrm{~cm}$.

\section{Isolation of the pathogen}

White cotton like mycelium, latter becoming gray, was observed on medium PDA. Sclerotia formation was observed after 2 weeks. Isolates ss-1, ss-2, ss-3, ss-4 and ss-5 on PDA formed bigger sclerotia, located circularly mostly at the edges of the Petri dishes (Figure 4). Isolates sm-1, sm-2, sm-4 and sm-5, formed smaller and more numerous sclerotia spread on the entire surface of the plate, forming aggregate forms consisting of several sclerotia (Figure 4).

\section{Sclerotinia spp. inoculum and carpogenically germination of sclerotia}

Apothecia formation from the sclerotia where observed after 7-8 weeks. The apothecia matured after 2 weeks. Apothecia produced from isolates ss-1, ss-2, ss-3, ss-4 and ss- 5 showed the prosenchyma turning out to the apothecial surface. Microscopic observation of the asci showed the presence of 8 ascospores with two nuclei. Apothecia formation from isolates sm-1, sm-2, sm-3, sm-4 and sm-5 showed ectal excipulum at the margin of the apothecium and the presence of globose cells. Ascospores were hyaline, and had four nuclei. 


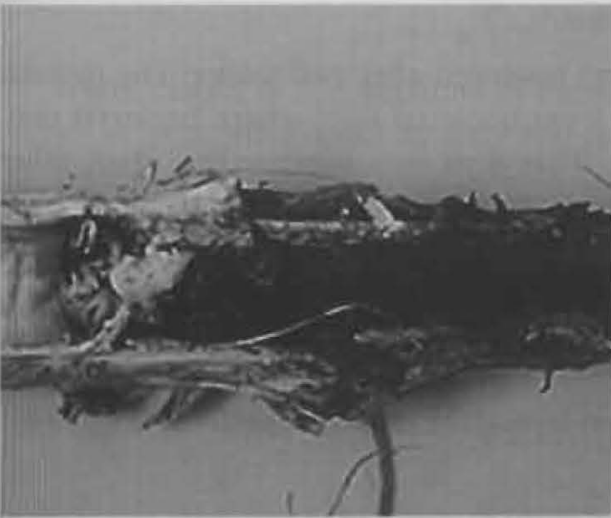

Figure 1: Symptom from S. sclerotlorum on the lower part of the stem and the presence of sclerotia

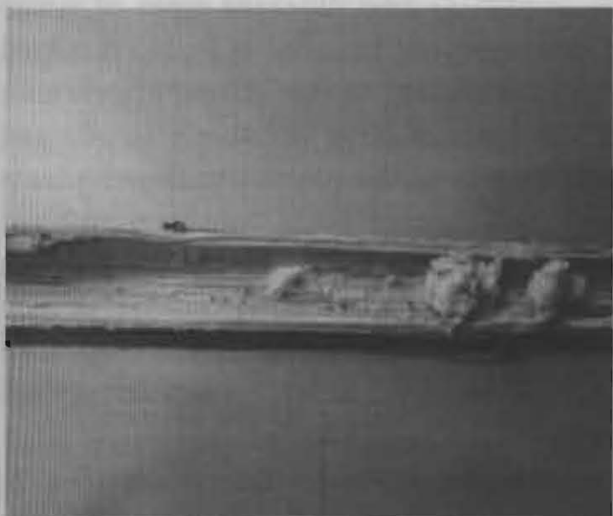

Figure 3: Sclerotia of S. minor inside the sunflower stem

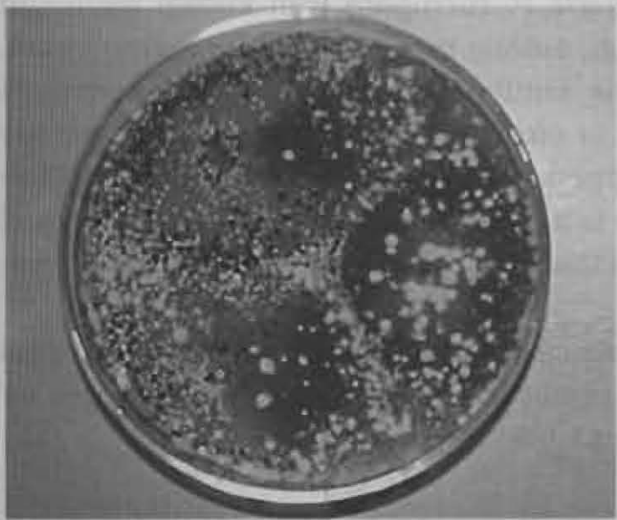

Figure 5: Sclerotia of S. minor, tsolate sm-1

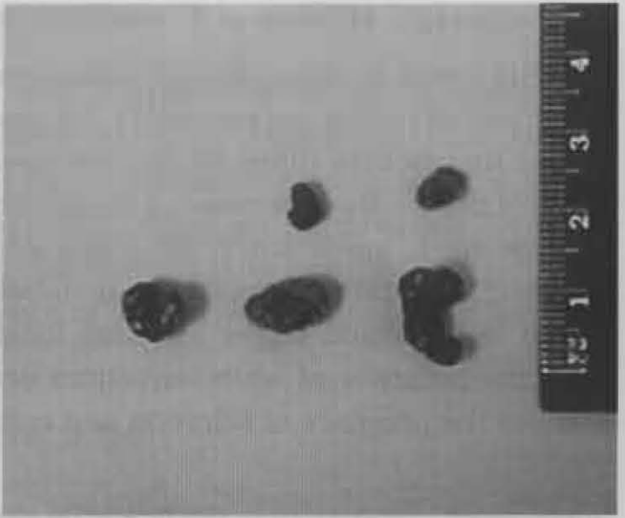

Figure 2: Sclerotla from S. sclerotlorum different in size and shape

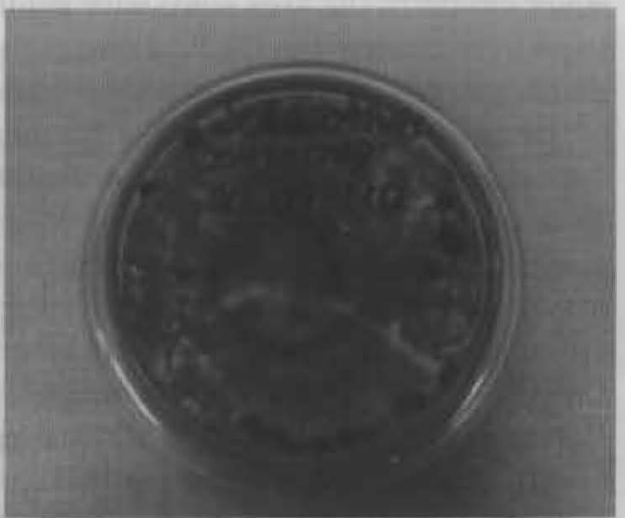

Figure 4: Sclerotia of S. sclerotiorum, isolate ss-1

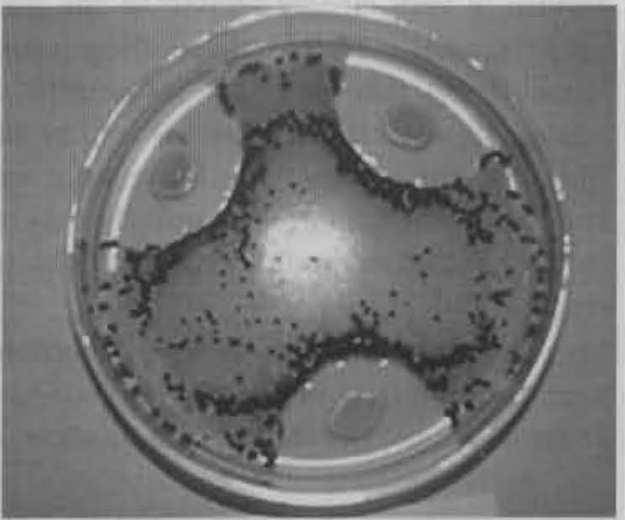

Figure 6: Antifungal efficacy of P. mediterranea against $S$. minor 


\section{Antifungal efficacy of $\boldsymbol{P}$. mediterranea}

The result of the antifungal efficacy was observed after two weeks. The mycelia in all isolates were suppressed $1-1.5 \mathrm{~cm}$ from bacterial spot where bacterial antifungal metabolites differ in the medium. This area was more yellow than other parts of the medium because of the lipopolypeptide production of the bacteria. Sclerotia at sm-1, sm-2, sm-3, sm-4 and sm-5, were formed and concentrated on the "border" with diffused antifungal metabolites (Figure 6). Isolates ss-1, ss-2, ss-3, ss4 and ss -5 formed bigger sclerotia located on the edges, in all three repetitions. Only the presence of white mycelium occurred in the Petri dish. Positive controls showed the presence of sclerotia and cotton like white to gray mycelium (Figure 6).

\section{DISCUSSION}

The investigation in the field and in vitro conditions showed the presence of white mould in the area sown with sunflower plants. Two different types of symptoms were observed in the field and in the laboratory. In the area of Prilep diseased plants showed typical symptoms of white mould: wilting of the leaves, appearance of the cancer in the lower part of the stem, presence of large variable sclerotia and appearance of white mycelium on the infected parts of the plant. Sunflower plants from other investigated areas showed longer and thinner stem than in uninfected plants, a very small pit and small sclerotia not bigger than $2 \mathrm{~mm}$. Thus, we assumed that maybe two different varieties were present causing disease of sunflower crops in R. Macedonia. The laboratory and in vitro investigation confirmed the presence of two different varieties of Sclerotinia spp.: Sclerotinia sclerotiorum (Lib.) de Bary and Sclerotinia minor Jagger.

An attempt to suppress the disease was conducted in in vitro conditions. In order to decrease the application of fungicide. Four isolates from the plant and soll pathogen Pseudomonas mediterranea were used as an antifungal agent. This bacterium is very closely related to the bacteria $P$. corrugata well known antifungal agent against various plant pathogen fungi, among them Sclerotinia sclerotiorum. Considering this data, we investigate the antifungal ability of $P$. mediterranea against $S$. sclerotiorum and $S$. minor in in vitro condition. The result which was obtained showed that this bacterium, suppressed the growth of mycelium and formation of sclerotia in vitro and that there is a possibility for it to be used to control "white mould" in sunflower in the field. In that case, additional tests should be conducted.

We think that Pseudomonas mediterranea can be considered as an antifungal agent against Sclerotinia spp. because it is soil and water bacterium, pathogen for tomato and pepper, but not for sunflower plants. 


\section{CONCLUSION}

White mould in the Republic of Macedonia is caused by the ascomycetes Sclerotinia sclerotiorum (Lib.) de Bary and Sclerotinia minor Jagger, order Helotiales.

Preliminary investigations showed that Pseudomonas mediterranea Cattara et al., 2002 can be considered as a biological control agent for suppressing the white mould and the pre laboratory investigation did show positive results.

This is the first report about the presence of Sclerotinia minor in the Republic of Macedonia.

\section{REFERENCIES}

Boland, G.J., Hall, R., 1994. Index of plant hosts of Sclerotinia sclerotiorum. Can. J. Plant. Pathology 16: 93-108.

Cobb, A.C., and Dillard, H.R., 2004. Production of apothecia and ascospores of Sclerotinia sclerotiorum. The plant health instructor. Available on line at http://www.apsnet.org.

Tourneau, D.L., 1979. Morphology, citology and physiology of Sclerotinia species in culture. Phytopathology 69(8): 887-890.

Gulya, T., Rashid, K., Mašırević, S., 1997. Sunflower diseases. In: Schneiter, A.A. [ed.] Sunflower Technology and Production. Agron. Monogr. 35, ASA, CSSA, and SSSA, Madison, Wl, USA, pp..21-65.

Chang, H.H. and Chang, C., 2003. Effect of relative humidity on myceliogenic germination of sclerotia of Sclerotium minor. Plant Pathology Bulettin 12: 65-68.

Kohn, L.M., 1979. Delimitation of the economically important plant pathogenic Sclerotinia species. Phytopathology 69(8): 881-886.

Maširević, S.. Gulya. T., 1992. Sclerotinia and Phomopsis two devastating sunflower pathogens. Field Crops Research 30(3-4): 271-300.

Melzer, M.S.. Smith, E.A. and Boland, G.J., 1997. Index of Plant Hosts of Sclerotinia minor. Can. J. of Plant Pathology 19: 272-280.

Nelson, B., and Lamey, A., 2000. Sclerotinia diseases of sunflower. North Dakota State Extension Service Bulletin, pp. 840.

Purdy, L.H., 1979. Sclerotinia sclerotiorum: History, Diseases and Symptomatology Host Range, Geographic Distribution, and Impact. Phytopathology 69(8): 875-880.

Statistical review: Agriculture. State statistical office of the Republic of Macedonia. Skopje. 2009. Available on line at http://www.stat.gov.mk.

Wu, B.M., Peng, Y., Subbarao, K.V., 2007. Incubation of excised apothecia enhances ascus maturation of Sclerotinia sclerotiorum. Mycologia 99(1): 33-41. 